\title{
Interpretasi Dialog Antar Agama Dalam Berbagai Prespektif
}

\author{
Ananda Ulul Albab \\ UIN Sunan Ampel Surabaya \\ aanandaulul@gmail.com
}

\begin{abstract}
;
Conflicts that occur between religious communities are often caused by small problems and misunderstandings of words or actions carried out between religious people. Though harmony is an important foundation in this nation. Therefore, dialogue is present to rebuild good relations between fellow believers. Not to look for differences then to harm it. But to look for differences that exist then embrace and love each other. Dialogue also functions to build relationships that are not only in one religion, but also outside the religion. So between Islam, Christianity, Catholicism, Buddhism, Hinduism and Confucianism can always communicate well. Remembering religion is indeed not to teach divisions but to lead every Ummah to uphold humanity. Although each religion is different in its teaching, but there are still the same aspects in terms of humanity, such as teaching love, compassion, sacrifice, mutual respect between others, giving selflessly, and many more good things taught by religion. The dialogue has different meanings and meanings depending on who interprets and gives his thoughts. It also depends on the background of the person who sparked an understanding of dialogue. In this article we will discuss dialogue according to the views of several religious leaders.
\end{abstract}

Keywords: Meaning, Dialogue, Religion

\begin{abstract}
Abstrak;
Konflik yang terjadi antatr umat beragama sering disebabkan persoalan-persoalan kecil serta kesalahpahaman perkataan atau perbuatan yang dilakukan antar umat beragama. Padahal kerukunan merupakan pondasi penting dalam bangsa ini. Maka dari itu, dialog hadir untuk membangun kembali hubungan yang baik antar sesama pemeluk agama. Bukan untuk mencari perbedaan kemudian mencelanya. Namun untuk mencari perbedaanperbedaan yang ada kemudian saling merangkul dan saling menyayangi. Dialog juga berfungsi untuk membangun relasi yang tidak hanya pada satu agamanya saja, tapi juga diluar agamanya. Jadi antara Islam, Kristen, Katolik, Buddha, Hindu, dan Khonghucu bisa selalu berkomunikasi dengan baik. Mengingat agama ada memang bukan untuk mengajarkan perpecahan melainkan untuk mengantar setiap umat menjunjung tinggi kemanusiaan. Walaupun setiap agama berbeda dalam pengajarannya, tapi tetap saja ada aspek-aspek yang sama dalam hal kemanusiaan, seperti mengajarkan cinta kasih, kasih sayang, pengorbanan, saling menghormati antar sesama, memberi tanpa pamrih, dan masih banyak lagi hal-hal baik yang diajarkan oleh agama. Adapun dialog memiliki pengertian dan makna yang berbeda-beda tergantung siapa yang menafsirkan dan memberi pemikirannya. Juga tergantung latar belakang orang yang mencetuskan pengertian tentang dialog. Dalam artikel ini akan dibahas tentang dialog menurut pandangan dari beberapa tokoh agama.
\end{abstract}

Kata kunci: Makna, Dialog, Agama,

\section{Pendahuluan}

Di Indonesia yang kaya akan berbagai macam penganut agama. Mulai dari Islam, Protestan, katolik, Khonghucu, Hindu, dan Buddha tidak mungkin dalam keseharian mereka hanya berkomunikasi dengan antar agamanya saja. Beberapa penganut dari masingmasing agama pasti hidup di lingkungan yang memiliki teman beda agama, seperti di 
sekolah, lingkungantempattinggal, kantor, dansebagainya. Hal tersebut dapat dikatakan sebagai dialog. Karena dalam sebuah pembicaraan pasti ada dua orang atau lebih. Dalam dialog yang terjadi antar individu atau kelompok difungsikan untuk membangun keharmonisan dalam sebuah hubungan. Entah itu pertemanan, persahabatan, atau persaudaraan. Dialog ada untuk membuat setiap umat belajar tentang mendengarkan, memahami, pemikiran-pemikiran, sertapendapat-pendapat yang bermacam-macam. Agar kebenaran tidak dimiliki oleh dirinya sendiri.

Berbicra tentang dialog, setiap agama memiliki pandangannya sendiri tentang dialog, juga setiap agama memiliki para tokoh pemuka agama yang turut menyumbangkan pemikiran mereka tentangapaitu dialog. Di mana para tokoh agama itu menginginkan sebuah dialog yang terjadi antarumat beragama atau agama dapat dijadikan jembatan untuk jalan agar tidak terjadi yang namanya konflik. Mudahnya, dialog adauntukmembangunkerukunan di Indonesia. Agar, hidup tak hanya tentang mana yang benar mana yang salah. Tapi bagaimana kebenaran dalam diri tidak dijadikan alat untuk mengkafirkan orang lain atau menyalahkan keyakinan mereka.

Setiap agama terkandung dua macam kecenderungan ajaran, yang tampak saling bertentangan. Pertama, kecenderungan yang mengajarkan bahwa agama yang dianut oleh seseorang adalah agama yang paling benar, mutlak, superior, dan menyelamatkan. Sedangkan orang-orang yang beragama lain adalah sesat, kafir, celaka, dan harus dijauhi atau dibujuk agar mengikuti agamanya. Kedua, ajaran bahwa setiap orang harus menghormati, dicintai, tidak ada paksaan dalam agama, dan dianjurkan berbuat bebajikan kepada siapa saja, bahkan kebaikan ini dianggap sebagai inti dari ajaran setiap agama. ${ }^{1}$

Seperti yang dilakukanoleh para orang yang anti agama, yang menurutnya, agama ada untuk mengawal sebuah peperangan, bahkan agama adalah pemicu utamanya. ${ }^{2}$ Padahal agama kan ada untuk mengontrol umat manusia agar hiduplebihbaiklagidanmemiliki rasa kemanusiaan yang tinggi. Untuk itu, setiap agama mengajarkan untuk berusaha menjaga keharmonisan antar umat beragama, melalui dialog salah satunya.

Sebelum munculnya pemikiran-pemikiran baru dalam perwujudan sikap terbuka terhadap perbedaan, situasi yang terjadi pada umat Islam di Indonesia diwarnai dengan pengajaran keagamaan yang lebih terpaku pada fikih. Serta pengajaran agama hanya terbatas pada tokoh- tokoh tertentu. ${ }^{3}$ Maka dari itu, Penulis akan coba membahas tentang dialog baik itu antar agama, antar umat beragama, maupun dialog lintas iman, menurut pandangan beberapa tokoh-tokoh agama yang telah menyumbangkan pemikirannya menegenai dialog. Agar pembacamengetahuibagaimanapemikiran-pemikiran yang lain dari masing-masing agama.

\section{Dialog Antar Agama}

Dialog memiliki arti “dialeghe”sedang berdiskusi, berbicara aspek-aspek yang menjadi persoalan, saling mengutarakan pendapat guna sama-sama saling memperbaiki secara bersama-sama. ${ }^{4}$ Dialog mulai ada dan berkembang sekitar tahun 1960an. ${ }^{5} \mathrm{Abu}-$

\footnotetext{
1 Burhanuddin Daya, Agama Dialogis: Merenda Dialektika Idealita dan Realita Hubungan Antaragama, (Yogyakarta: Mataram Minang Lintas Budaya, 2004), 1.

2Sam Harris, The End of Faith: Religion, Terror, and the Future of Reason (New York, NY: W. W. Norton, 2005), 25.

${ }^{3}$ Muna Hayati, RETHINKING PEMIKIRAN A. MUKTI ALI (Pendekatan Scientific-Cum-Doctrinaire dan Kon-sep Agree in Disagreement), diakses dari bttps:// www.researchgate.net/publication/327600327 MENGINGAT KEMBALI PEMIKIRAN ABDUL MUKTI ALI PENDEKATAN SCIENTIFIC-CUM-DOCTRINAIRE DA-N KONSEP AGREE IN DISAGREEMENT, 25 Desember 2018, 14:40.

${ }^{4}$ Lathifatul Izzah, "Melihat Potret Harmonisasi Hubungan Antarumat Beragama Di Indonesia", Religi, Vol IX, No. 1, (Januari 2013), 8.
} 
Nimer mengatakan awal mula dialog antar agama ada karena kalangan Kristen ingin bisa diterima dengan baik oleh setiap negara. Yang mana mereka juga ingin memperlihatkan bahwakalangan merekatidak ada yang memiliki niat untuk menggoyahkan keimanan seseorang pemeluk agama dari selain Kristen. ${ }^{6}$

Dialog merupakan hal yang sangat penting dan merupakan jalan alternatif ideal dalam berperan menyelesaikan konflik antarumat beragama. Yang di mana fenomena konflik antarumat beragama harus segera diselesaikan agar tidak menjadi dampak yang negatif dalam kehidupan. Pada perkembangannya ternyata dialog tingkatan agama menuntut supaya setiap pihak menghormati pemeluk agama lain untuk mendalami keyakinannya dan mengamalkan keyakinannya tersebut tanpa ada rasa curiga-mencurigai. ${ }^{7}$

Adapun, jika dalam konteks agama sebuah dialog akanmenuntut semua pihak agar menghargai kebebasan. Misalnya, setiap orang berhak mengemukakakn pendapatnya secara bebas. Bahkan boleh membahas hal-hal mengenai teologi setiap agama. Dialog agama menjadi suatu perjumpaan di mana semua yang ikut berdialog berkawan satu sama lain walau berbeda agama. ${ }^{8}$ Olaf Schumann dan Paul F. Knitter, menegaskan bahwa dialog bukan ajang untuk berdebat, berpolemik apalagi memaksakan pandangannya kepada pihak lainnya. Karena seharusnya individu atau kelompok yang berdialog dapat saling memahami antar sesama tentang pengalaman kehidupan keberagamaan mereka. ${ }^{9}$

Dialog diharap mampu menjadi penerangan jalan yang terang bagi kemanusiaan yang ada pada setiap agama. Dengan dialog antar agama, antar pemeluk agama diharapkan dapat bersikap lebih toleran terhadap pemeluk agama lain. Agama harus menjadi wacana spiritual yang menghadirkan rasa damai dan aman, bukannya perang dan pertikaian. Harus diingat, bahwa setiap manusia mempunyai tanggung jawab untuk menolak dengan tegas bentuk diskriminsi dan intoleransi atas nama agama dan kepercayaan, sekaligus meneguhkan fungsi agama dan kepercayaan sebagai pendukung kemuliaan manusia dalam misi membangun perdamaian. ${ }^{10}$ Seperti halnya agama, yang memang fungsinya untuk menerangi kehidupan manusia.

Perlu dimenegerti bahwa di Indonesia memang negara yang pluralis, warganya harus menanamkan sikap pluralisme seperti yang dikatakan Kuntowijoyo yang ditulis Lani Rofiqoh dan Aris Suherman, bahwa pluralitas merupakan suatu kemajemukan yang tidak boleh disangkal, seperti adanya laki-laki dan perempuan, ada yang muda dan tua, perbedaan warna kulit yang berasal dari setiap daerah, kepercayaan dan keyakinan masig-masing orang yang berbeda. Hal tersebut merupakan suatu keadaan nyata adanya pluralis di Indoensia. Jadi, salah apabila perbedaan dimaknai sebagai sesuatu yang dikatakan menghancurkan. ${ }^{11}$

Terdapat salah satu bukti kemajemukan penduduk Indonesia dilaporkan bahwa penduduk Indonesia terdiri dari lebih 740 suku bangsa atau etnis, 583 bahasa dan dialek dari 67 bahasa induk yang digunakan berbagai suku bangsa. Selain itu terdapat pemeluk

\footnotetext{
5 J.B. Banawiratma, dkk, Dialog Antarumat Beragama, Gagasan dan Praktik. Di Indonesia, Cet-1(Jakarta: Mizan Publika, 2010), vii.

6 Akhmad Rizqon Khamami, "Dialog Antar Iman Sebagai Resolusi Konflik, Tawaran Mohammed AbuNimer", Al-Tabrir, Vol 14, No. 2, (Mei 2014), 252.

7Zubaidi, Islam dan Benturan Antar Peradaban, (Yogyakarta: ARR- RUZZ MEDIA, 2007), 47-51.

${ }^{8}$ Akhmad Rizqon Khamami, 209.

9 Anas Aijudin, "Mengelola Pliralisme Melalui Dialog Antar Agama” ... 121.

${ }^{10}$ Moh. Shofan, Jalan Ketiga Pemikiran Islam, (Yogyakarta: IRCiSoD, 2006), 208-216.

11 Lani Rofiqoh, Aris Suherman, "Peran Pendidikan Ilmu Pengetahun Sosialdalam Membentuk Karakter Pluralis Siswa Di Mts N 11 Cirebon”, Edueksos, Volume Vi, No 2, (Desember 2017): 140
}

24 | Ananda Ulul Albab, - Interpretasi Dialog Antar Agama Dalam Berbagai Prespektif 
agama yang beragam pula seperti Hindu, Buddha, Khonghucu, Islam, Kristen dan Kaolik, dan beratus agama dan kepercayaan lokal yang menjadi bagian dari kebudayaan. ${ }^{12}$

Padahal, jika ingin suatu negara itu harmonis, warganya harus menanamkan sikap toleransi. Yang pada negara ini toleransi memang pondaai penting dalam menjaga keharmonisa di dalam keragaman agama yang berkembang di Indonesia. Seperti, Islam, Kristen, Khonghucu, Hindu, Budha, Katolik. ${ }^{13}$

Dialog antar agama sangat penting keberadaannya. Hal ini dilakukan dengan landasan: Pertama, konflik agama, yang pada dasarnya berasal dari doktrin-doktrin teologi yang bersifat eksklusif. Kedua, perdamaian. Tinjauan lebih dalam lagi tentang konflik antar agama dan manusia ini dapat diterangkan dengan mengembalikan pada sifat alami atau dasar manusia yang selalu berselisih dan bersengketa. Disamping itu, ternyata juga manusia mempunyai sifat dasar ingin terwujudnya perdamaian. Oleh karena itu dicarilah suatu upaya untuk menyelesaikan masalah tersebut. Ketiga, Ajaran agama. Agama mengajarkan kepada pemeluknya untuk melakukan dialog baik antar sesama maupun antar agama. Keempat, pluralitas agama, setiap agama lahir dalam sebuahlingkup sejarah dan menciptakan tradisi. Landasan dialog yang. Kelima yaitu titik temu agama-agama. ${ }^{14}$

Dialog antar umat beragama membantu untuk meningkatkan kerjasama antar semuanya. Sehingga semua kalangan dapat bersama-sama menegakkan kemanusiaan, keadilan, perdamaian, dan persaudaraan. ${ }^{15}$

Dialaog antar agama memiliki tujuan untuk memberikan pemahaman terkait ajaran dalam kehidupan dari masing-masing agama, bukan untuk beradu argument dan berusaha melahirkan siapa yang benar dan siapa yang salah apalagi memaksa untuk salah satu mengikuti ajaran agamanya. ${ }^{16}$

Adapun dalam lingkup pembahasan yang pertama, dialog teologis yang bertujuan untuk membangun kesadaran bahwa diluar keyakinan dan keimanan diri. Dialog teologis diharap bisa menempatka imannya ditengah iman lainnya dan batasan yang ada hanya pada kutab suci. Kedua, dialog non-teologis, berupa kemanusiaan dan mencakup segala hal yang berkaitan dengan kehidupan. ${ }^{17}$

Dialog antar agama jika dalam pandangan agama Kristen itu, seperti berdiskusi tentang persoalan-persoalan yang ingin diselesaikan bersama. Hal tersebut melibatkan tokoh-tokoh atau umat dari agama lain, yang kemudian membicarakan tentang bagaimana supaya dapat hidup dengan nyaman dan menyenangkan bersama-sama, berdampingan tanpa adanya konflik. ${ }^{18}$

\section{Dialog Menurut Para Tokoh}

Dalam setiap kehidupan bermasyarakat kita akan menemukan berbagai macam suku, ras, ras, budaya, bahasa dan lainnya yang sudah menjadi pendamping setiap fenomena

12 Dody S Truna, Pendidikan Agama Islam Berwawasan Mutikulturalisme (Jakarta: Badan Litbang dan Diklat Kementerian Agama RI, 2010), 1.

13 Lathifatul Izza, "Melihat Potret Harmonisasi Hubungan Antar Umat Beragama Di Indonesia", Religi, Vol IX, No. 1, Januari 2013: 4

${ }^{14}$ Muhammad Zainal Arifin, Naskah Publikasi: Dialog Antar Agama dalam Pandangan Hans Kung, 7. Diakses dari bttp://eprints.ums.ac.id/20437/22/NASKAH_PUBLIKASI.pdf, 25 Desember 15:00.

15 Hans Kung, "Perdamaian Dunia, Agama-Agama Dunia, Etika Dunia", Terj Ali Noer Zaman Agama Untuk Manusia, loc. cit. 70-71.

${ }_{16}$ Burhanuddin Daya, Herman Leonard Beck, Ilmu Perbandingan Agama Di Indonesia Dan Belanda, (Jakarta: Inis, 1992), 208.

17 Zakiyuddin Bhaidawy, Dialog Global dan Masa Depan Agama, (Surakarta: Muhammadiyah University Press, 2001), 29.

${ }^{18}$ Khadijah Mohd Khambali, Nurhanisah Senin, Citra Dialog Antar Agama dalam Perspektif Islam dan Kristian: Analisis Awal, diakses dari http://journalarticle.uk.m.my/5957/1/j.pdf, pada 25 Desember 2018, pukul 18.00 WIB. 
sosial di masyarakat, mengingat Indonesia merupakan negara yang bhinnneka tunggal ika seperti itulah semboyan nya kaya akan segalanya namun tetap satu yaitu Indonesia. Perbedaan kadangkala membuat indah pemandangan apabila bisa menjadi corak yang teratur yakni perbedaan masyarakat tetap bisa hidup saling rukun akan tetapi di sisi lain perbedaan juga dapat dijdikan sebagai pemecah terlebih hal itu mengenai keyakinan, Indonesia adalah penduduk yang yang sangat sensistif bila menyinggung masalah keyakinan oleh sebab itu maka perlu adanya pemahaman-pemahaman suatu teori yang dapat menyelesaikan suatu koflik keagamaan.

Permasalahan berawal seorang tokoh yang bernama sam harris, ia berlatar belakang new-atheis mengemukakan pendapat bahwa adanya agama justru hanya sebagai fenomena untuk menimbulkan ketegangan terhadap anatar pemeluk agama. Yang mana agama mengundang terjadinya konflik yang berujung pada permusuhan dan perpecahan. Agama lah yang menjadi pusat peperangan. ${ }^{19}$ Ditengah kemelud yang dilontarkan oleh penganut atheis mengenai agama kemudian muncul tokoh yang dalam hal ini memberikan pencerahan terhadap umat beragama.

Knitter menegaskan bahwa suatu dialog antar-agama yang soteriosentris yang memiliki tanggung jawab global sebagai konteksnya, titik berangkatnya, dan tujuannya adalah dialog di mana praksis memainkan peranan penting. Knitter mendesak suatu dialog di mana umat dari berbagai agama yang berbeda tidak bisa berbicara secara religius atau teologis kecuali dalam praktik mereka juga (dan ini yang terutama) bertindak bersama demi kesejahteraan dunia. ${ }^{20}$

Adanya fakta Negara Indonesia merupakan negara kepulauan, merupakan alasan mengapa kemajemukan sosial-budaya dan agama menjadi sesuatu yang harus diperhitungkan dan diperhatikan. Kondisi kemajemukan tersebut mengharuskan segenap komponen bangsa berbuat sesuatu secara realistis untuk mencari dan menemukan titik pandang yang sama di antara mereka. Hal itu perlu dilakukan karena setiap kelompok tentu akan melakukan sesuatu berdasarkan prinsip dan pandangan masing-masing. Kondisi tersebut akan menimbulkan perbenturan berbagai kepentingan dan tujuan yang dapat memicu konflik dan perselisihan yang berkepanjangan. ${ }^{21}$

\section{Pandangan Abu Nimer}

Abu Nimer adalah salah satu tokoh dialog lintas iman yang menyumbangkan pemikirannya tentang dialog. Bagi Abu-Nimer, dialog antar-iman adalah sarana untuk menciptakan perdamaian di dunia. Dengan dialog, menurut AbuNimer, manusia dapat menghindari permusuhan dan kekerasan atas nama agama. Dengan meminjam teori pluralisme, menurut penulis, Abu-Nimer masuk dalam kategori pluralisme komunikatif yang menggabungkan kubu partikularis dan kubu universalis. Pemikiran Abu-Nimer menggambarkan pendekatan yang unik dan menarik dibanding dengan pemikiran tokoh antar-iman lainny. Dialog sebagai solusi untuk mengahdirkan kesadaran akan toleransi dan menghormati agama lain, berbeda dengan konsep debat yang mana debat dianggap memiliki potensi menolak orang lain yang berasal dari keyakinan agama berbeda. ${ }^{22}$ Bagi Nimer dialog antar iman adalah sebuah refleksi dari munculnya konflik yang terjadi pada

\footnotetext{
${ }^{19}$ Sam Harris, The End of Faith: Religion, Terror, and the Future of Reason (New York, NY: W. W. Norton, 2005), 25.

${ }^{20}$ Lih. Paul F. Knitter, Satu Bumi Banyak Agama: Dialog multi-Agama dan Tanggung Jawab Global (Jakarta: BPK Gunung Mulia, 2012), 122.

${ }^{21}$ Nurcholish Madjid, Islam Doktrin dan Peradaban (Jakarta: Paramadina, 1992), xviii-xx.

${ }_{22}$ Mohammed Abu-Nimer, Amal Khoury and Emily Welty, Unity and Diversity (Washington, D.C.: United States Institute of Peace Press, 2007), 8.
}

26 | Ananda Ulul Albab, - Interpretasi Dialog Antar Agama Dalam Berbagai Prespektif 
komunita yang mengalami perpecahan agar dapat saling memahami satu sama lain. Ternyata kenyaatan dilapangan menunjukkan bukti yang sebaliknya. Bagi yang tidak paham akan konsep dialog antar iman tujuan yang sebenarnya baik malah menjadi buruk, dimana dialog antar iman nyatanya membuat masyarakat resah curiga bahwa jangan-jangan mereka dipengaruhi agar berpindah keyakinan.

Seperti halnya yang dikatakan Gus Dur tentang pluralisme, bagi beliau semua agama itu tidak sama, karena secara teologis dalam setiap aqidah tidak di benarkan apabila sampai menganggap bahwa semua agama itu sama, tapi setiap agama pasti mengajarkan untuk berlaku baik walau berbeda keyakinan. ${ }^{23}$

Adanya dialog di semua tataran, khususnya di tengah situasi konflik, memberi dampak pada perubahan pada artikulasi bahasa dan wacana yang beredar di tengah masyarakat, yaitu perubahan dari mengingkari sosok lain dan menggunakan retorika agama untuk memobilisasi perilaku kekerasan menjadi masyarakat yang terbentuk dengan damai dan saling menghargai. Bahkan ketika para petinggi bertemu, maka akan tercipta perubahan dalam struktur konflik ${ }^{24}$. Dialog antar iman sifatnya lebih luas tidak hanya terpaku pada pembahasan dan diskusi akan tetapi lebih kedepannya terarah kepada implementasi. Yakni bagaimana caranya setelah dibicarakan lalu bisa terwujud dalam aksi yang semua bisa berpartisipasi untuk mengeluarkan pendapat.

Terdapat beberapa aturan yang perlu diperhatikan apabila melakukan dialog antar iman yakni: ${ }^{25}$ Pertama, faktor kognitif, yang mana faktor ini bersifat afektif serta berpoytensi untuk merubah sikap seseorang. Kedua, bagaimana cara untuk mengevektifkan peserta dialog secara individu maupun perwakilan dari suatau komunitas. Ketiga, Keefektivan belajar melalui pengalaman dibanding dengan belajar melalui instrumental lainnya.

Abu nimer mengemukakan pendapatnya tentang dialog antar iman. Beliau menyebut dialog antar-iman sebagai tract two diplomacy. ${ }^{26}$ Di mana dialog dapat dilakukan tanpa membawa nama-nama kelembagaan yang ada. Pertemuan para petinggi agama menjadi simbol dukungan mereka terhadap toleransi beragama. Dialog antar-iman juga tidak terbatas hanya Kristen dan Islam saja. Dialog melibatkan Yahudi, Hindu, Buddha dan agama lainnya. Walaupun, Abu-Nimer mengakui bahwa sesungguhnya dialog antar-iman, ataupun dialog antar-agama, bermula dari kalangan Kristen. Ia menyatakan bahwa dialog antar-iman dimunculkan agar misionaris Kristen dapat diterima dengan tangan terbuka di negara-negara ketiga saat mereka melakukan aktivitas kemanusiaan di negara tersebut. Melalui penggunaan dialog antar-iman ini, mereka ingin memperlihatkan kepada kalangan non-Kristen bahwa misionaris Kristen dapat melakukan aktivitas di tengah-tengah masyarakat agama lain tanpa merusak keimanan seseorang. Pada tahun 1948 Dewan Geraja Dunia (World Council Church) dibentuk di Amsterdam sebagai respon atas memburuknya kerja minisonaris Kristen. Dalam rangka mencari cara agar minisionaris Kristen dapat bekerja lebih baik dengan kalangan non-Kristen demi kemaslahatan dan kebaikan umat manusia, organisasi ini mengadakan konferensi di India (1961) dan Sri Langka (1967). Dekrit Nostra Aetate pada Dewan Vatican Kedua, ungkap Abu-Nimer, berpengaruh pada perubahan sikap Katolik dalam mendukung dialog antar-iman. ${ }^{27}$

\footnotetext{
2323 Eko Setiawan, "Konsep Teologi Pluralisme Gus Dur Dalam Meretas Keberagaman Di Indonesia”, Asketik, Vol. 1 No. 1, (Juli 2017): 62.

${ }^{24}$ Akhmad Rizqonn Khamami, dialog antar iman sebagai resolusi konflik, tawaran Mohammed Abu-Nimer, Al-Tahrir, vol. 14, No. 2 (Mei 2014), 257.

25258.

${ }^{26}$ Mohammed Abu-Nimer, Amal Khoury and Emily Welty, Unity and Diversity (Washington, D.C.: United States Institute of Peace Press, 2007), 7.

27 Abu Nimer, 27.
} 
Tujuan dari dialog antar-iman ialah memunculkan sikap toleransi dan pluralisme agama dalam kehidupan bermasyarakat. Abu-Nimer meminjam teori Developmental Model of Intercultural Sensitivity (DMIS) yang digagas Milton J. Bennett. Bahwa kompleksitas pengalaman individu tentang perbedaan berdampak pada kemampuan dalam memahami "kelompok lain", begitu juga kemampuan dalam melibatkan diri ke tengah interaksi interkultural. Teori ini menegaskan bahwa perspektif universal seseorang cenderung masuk ke dalam salah satu dari tiga kategori berikut ini, yaitu: ethnocentric, enthnorelative, atau transitional. ${ }^{28}$

\section{Pandangan Mukti Ali}

Mukti Ali lahir di Desa Balun Sudagaran Cepu pada 1923 dan termasuk keluarga yang berada. Desa yang ditinggalinya terkenal sebagai daerah saudagar. Ayahnya bernama H. Abu Ali adalah seorang saudagar tembakau terbesar di Cepu, dan sangat kental dalam hal agama. Ibunya bernama $\mathrm{H}$. Khadidjah, adalah seorang ibu rumah tangga, sekaligus penjual kain. ${ }^{29}$ Mukti Ali merupakan sosok intelektual Muslim yang visioner, pluralis, disiplin, serta sangat menghargai ilmu. ${ }^{30}$

Pada saat menuntut ilmu di Kanada, Mukti Ali belajar tentang Pemikiran Islam Modern dalam asuhan Prof. Wilfred Cantwell Smith. Dan menyukai dua poin dari profesornya itu, pertama adalah metode penyajian perkuliahan, dan kedua adalah caranya dalam melakukan analisis. Smith melakukan aplikasi pendekatan komparatif (perbandingan), yaitu dengan melihat sesuatu dari berbagai aspek. Akhirnya A. Mukti Ali menemukan metode ilmu yang dicaricarinya selama ini dan dalam dua tahun ia berhasil menyelesaikan program masternya pada tahun 1957 dengan memperoleh gelar Master of Arts (M.A.), lalu kemudian ia pulang ke tanah air. ${ }^{31}$

Singgih Basuki memberikan penilaiannya tentang Mukti Ali bahwa beliau adalah seorang pemikir Islam Indonesia (1923-2004) yang berkarakter kuat, berpikiran modern, dan konsisten, fenomenal sosoknya bahkan sampai era sekarang ini. Usaha yang telah dilakukan Mukti Ali dalam mengembangakan Perbandingan Agama telah memberikan dampak yang sigfikan bagi berkembangnya wacana dialog dan kerukunan antar umat beragama di Indonesia. ${ }^{32}$

Prof. Dr. H. Abdul Mukti Ali (1923-2004), adalah orang yang pertama kali memperkenalkan ide-ide pemberuan pemikiran Islam di Indonesia. Ia menulis berbagai ide dan gerakan pembaruan di berbagai negara: Mesir, Indonesia, Pekistan, Turki. Secara khusus dia membandingkan gerakan pemikiran di Mesir yang lebih bercorak liberal di bidang pemikiran serta di Indonesia yang menempatkan arti Muhammadiyah sebagai gerakan yang bercorak dinamisme dengan semboyan "sedikit bicara banyak kerja." 33 Menekankan pentingnya pemahaman keagamaan secara tepat, dan obsesinya adalah ingin membangkitkan dialog antarumat beragama dalam rangka menghilangkan kecurigaan, sekaligus memantapkan pengetahuan tentang agama lain untuk menumbuhkan toleransi terhadap perbedaan agama. Mukti Ali, merupakan seorang sarjana Perbandingan Agama yang berhasil merintis hubungn antar agama di Indonesia dan menumbuhkan gairah di

\footnotetext{
28 Abu Nimer, 28.

${ }_{29}$ M. Damami dkk, "H.A. Mukti Ali: Ketaatan, Kesalehan dan Kecendekiaan" dalam Djam'annuri (ed.), 70 Tahun H.A. Mukti Ali: Agama dan Masyarakat, 4-6.

30 Azyumardi Azra \& Saiful Umam, Menteri-menteri Agama RI, Biografi Sosial Politi (Jakarta: PPIM, 1989), 273.

${ }^{31}$ M. Damami, "H.A. Mukti Ali: Ketaatan, Kesalehan dan Kecendekiaan”, 28-29.

32 Moh. Khoirul Fatih, diaog dan kerukunan umat beragama di Indonesia perspektif Mukti Ali, Madinah: Jurnal Studi Islam, volume 5 nomor 1 (juni 2018), 46.

33 Saidiman Ahmad, Husni Mubarak, dan Testriono (ed), Pembaharuan tanpa A pologia, Esai-esai tentang Ahmad Wabib, (Jakarta: Yayasan Wakap Paramadina, 2010), 269-270.
} 
kalangan akademisi untuk memperdalam pengetahuan dalam ilmu ini, sehingga ia dinobatkan sebagai Bapak Ilmu Perbandingan Agama di Indonesia. ${ }^{34}$

Mukti Ali dikenal sangat peduli dengan problem kerukunan hidup antarumat beragama di Indonesia yang pluralistik. Dalam konteks situasi ini dan 27 Al-Lubb, Vol. 1, No. 1, 2016: 24-42 kondisi historis bangsa yang sering terjadi ketegangan dan konflik antarumat beragama serta terdorong oleh naluri keilmuannya yang kuat, dia merespons dan berusaha memberikan sumbangan pemikiran terhadap problem tersebut dengan mencoba menciptakan dan mengajarkan konsep tentang kerukunan hidup antarumat beragama dengan ungkapan agree in disagreement. ${ }^{35}$ Yang maksudnya, setuju dalam ketidaksetujuan berlandas pada rasa saling menghargai dan menghormati perbedaan yang ada.

Baginya, ketika dialog dimaknai dengan dua orang atau lebih yang terlibat dalam suatu perbincangan yang saling aktif.Mukti Ali berpendapat dialog berarti "dia-leghe", sedang berbicara, berdiskusi, beralasan tentang aspek persoalan, yang di mana harus saling membetulkan jika salah dan bergerak bersama-sama. "concourse", memiliki arti berlari bersama, juga bergerak bersama, maju bersama, dan bukan hanya sekedar membangun pembicaraan tanpa ada I'tikad baik antar satu dengan yang lainnya. ${ }^{36}$

Mukti Ali juga berpendapat, bahwa dialog antar agama itu yang pertama, pertemuan hati dan pikiran antar pemeluk berbagai agama. Kedua, merupakan komunikasi antara orang-orang yang percaya pada tingkat agama. Ketiga, dialog merupakan jalan bersama untuk mencapai kebenaran dan kerjasama dalam proyek-proyek yang menyangkut kepentingan bersama. ${ }^{37}$ Mukti Ali juga mengungkapkan bahwa dialog antar agama merupakan suatu perjumpaan umat beragama di mana harus saling menghormati, serta saling mencintai antar pemeluk dengan tujuan supaya memperoleh titik temu dalam berbagai perbedaan dalam kenyataan pluralitas agama. ${ }^{38}$

Pernyataan-pernyataan tersebut berawal dari dialog antar agama yang diadakan di Beirut pada tahun 1970, dan konperensi yang diadakan di Kyoto pada tahun 1970, mengenai Agama dan Perdamaian (World Conference On Religion and Peace), Mukti Ali memberikan pernyataan:

"Salah satu hal yang perlu dicatat setelah Perang Dunia Kedua ini, ialah seringnya pertemuan-pertemuan atau kongres agama-agama antar bangsa diadakan. Pertemuan agama itu ada yang didatangi oleh kaum agama saja, dan ada pula selain kaum agama, juga ahli-ahli ilmu pengetahuan bukan agama. Dalam pertemuan agama seperti yang pertama itu, yang dihadiri oleh kaum agama, hal itu mungkin didorong oleh kesadaran bahwa manusia beragama dewasa ini tidak bisa hidup menyendiri dalam lingkungan agama yang dipeluknya. Mereka harus bergaul dengan kelompok manusia yang memeluk agama yang lain. Cara pergaulan itu harus dipikirkan dan direnungkan bersama, karena apabila ketegangan apalagi konflik antara satu kelompok pemeluk agama dengan kelompok pemeluk agama lain timbul, maka orang dapat mengetahui kapan konflik itu mula timbulnya, tetapi orang tidak bisa menduga kapan ia akan berahir. Adapun pertemuan yang sifatnya seperti yang kedua, yang dihadiri bukan hanya ahli-ahli agama, tetapi juga oleh ahli-ahli ilmu pengetahuan. rupanya hal itu terdorong oleh kedasaran

\footnotetext{
34 Azyumardi Azra, Menteri-Menteri Agama..., 286.

35 Singgih Basuki, Pemikiran Keagamaan A. Mukti Ali, 218.

${ }^{36}$ Mukti Ali, Agama, Moralitas dan Perkembangan Kontemporer, (Yogyakarta: Tiara Wacana, 1997) 7-8.

${ }^{37}$ Mukti Ali, Ilmu Perbandingan Agama, Dialog, Dakwah dan Misi, (Yogyakarta: Pustaka Anwar, 1983), 208.

38 Moh. Khoirul Fatih, "Dialog Dan Kerukunan Umat Beragama Di Indonesia (Perspektif Mukti Ali)” ... 51.
} 
bahwa agama harus juga berbicara tentang masalah-masalah dunia dan masalah yang dihadapi oleh umat manusia, diluar bidang agama." ${ }^{39}$

\section{Pandangan Hans Kung}

Hans Kung, lahir di Sursee- Sitzerland pada 19 Maret 1928 merupakan seorang ahli teologi controversial, dan pengarang yang produktif. Sejak 1995 dia menjadi pemimpin Yayasan Etika Global (Foundation for Global Ethic/Stiftug Weltethos). ${ }^{40}$

Bagi Hans Kung, dialog antar agama adalah sesuatu yang menuntut sikap terbuka dari pada defensif, semangat untuk belajar satu sama lain disertai dengan sikap rendah hati dari pada perasaan dirinya paling benar dan pada dasarnya dialog itu sebagai fungsi kritis beragama. ${ }^{41}$ Hans Kung juga mengatakan bahwa setiap orang beragama harus bisa membuktikan keimanannya meskipun dalam perbedaan yang ada. ${ }^{42}$

Dialog antar agama mempunyai fungsi kritis ad intra dan ad extra. Tapi tidak berarti bahwa dialog menjadi sarana untuk menentukan mana agama yang benar. Kalau kata agama dipahami secara kongkrit, bukan metafisis, maka dialog antar agama berarti dialog antar orang-orang beragama. Manusia mendapat tempat sentral dlam dialog, dengan syarat, manusia juga tidak dipahami secara metafisis, melainkan manusia yang kongkrit. Manusia kongkrit artinya, menunjuk orang-orang beriman dalam agama tertentu, dlam lingkungan budaya tertentu, dengan aspirasi tertentu dan pada masa tertentu. Dalam kekongkritannya inilah dialog mendapatkan tempat sebagai fungsi kritis. ${ }^{43}$

Dialog antaragama pada tataran teologis seringkali mengalami ketegangan dan kebuntuan bahkan kegagalan.

Selain dialog interreligius pada tataran teologis, dialog antaragama juga memiliki praksis tersendiri. Dialog praksis ini kadang disebut dialog etis atau ekumenis juga. Hans Küng dan Paul Knitter pun berada dalam model ini. Kita akan lihat satu demi satu. Pertama, teologi ekumenis. Keprihatinan Küng berawal dari tesisnya bahwa "tiada perdamaian di dunia ini jika tidak ada perdamaian di antara agama-agama, tiada perdamaian dalam agama-agama tanpa dialog, dan tiada dialog interreligius tanpa usaha untuk saling memahami satu dengan yang lain, dan tiada saling pengertian di antara agama-agama, bila tidak diusahakan upaya-upaya teologis yang bersifat ekumenis atau dialogis. Dalam keprihatinan Küng, tiada hal yang lebih pahit daripada perang yang disebabkan karena agama. $^{44}$

Dialog sebagai fungsi kritis tidak terlepaskan dari kehendak setiap orang untuk mencari kebenaran terus menerus. Kung mengingatkan bahwa kebenaran yang kita cari bukanlah kebenaran yang bersifat "ready-made". Kebenaran ini bukan seperti barangbarang jadi yang dijejer dalam suatu supermarket yang bisa kita ambil disaat kita membutuhkan. Tapi, kebenaran menampakkan diri dalam hidup sejarah, relasi dengan orang lain. Kebenaran tidak identik dengan doktrin atau tradisi. Dalam hidup beragama, doktrin atau tradisi agama (yang merupakan segi obyektif dan konstitutif agama)

\footnotetext{
39 A. Mukti Ali, Dialog Antar Agama, (Yogyakarta: Yayasan Nida, 1970), 1.

40 Khaira Husain, Etika Global; Sumbangan Hans Kung DALAM Dialog ANTAR Agama, 2. Diakses daribttps:// media.neliti.com/media/publications/40304-ID-etika-global-sumbangan-bans-kung-dalam-dialog-antaragama.pdf, 25 Desember 2018, 15:28.

${ }^{41}$ Hans Kung dan Karl Josef Kuschel, Etika Global (Yogyakarta: Pustaka Pelajar, 1999), 9.

42 Hans Kung, "Sebuah Model Dialog Kristen-Islam" dalam Jurnal Paramadina (Jakarta, Paramadina JuliDesember, 1998), 32 ,

${ }^{43}$ Khaira Husain, Etika Global;..., 9.

44 Armada Riyanto, "Sebuah Studi Tentang Dialog Interreligius," dalam Diskursus, Vol. 9, No. 2 (Oktober 2010): 251.
}

30 Ananda Ulul Albab, - Interpretasi Dialog Antar Agama Dalam Berbagai Prespektif 
mendapatkan maknanya yang paling dalam juustru dalam kaitannya dengan kehendak kita untuk mencari kebenaran terus menerus. ${ }^{45}$

\section{Dialog Perspektif Fethullah Gülen}

Fethullah Gülen lahir pada tahun 1938 di sebuah kota kecil yang dihuni oleh sekitar 50-60 kepala keluarga di Korucuk, Propinsi Erzurum. ${ }^{46}$ Fethullah Gulen diberi gelar sebagai penulis, penyair, pemimpin pembangkang, aktivis pendidikan, aktivis keamanan, serta tokoh ilmuwan Islam agung. Selain sebagai seorang pegiat dialog antar agama, Gülen adalah seorang penulis yang produktif. Ia menulis tidak kurang 60 buku, rekaman video dan audio yang berisi ceramahnya. ${ }^{47}$ Gulen menjadi sosok yang sangat menginspirasi setiap manusia dibelahan jiwa manapun. Hingga segala yang dia punya tersebut berpengaruh pada pergerakan masyarakat sivil dunia yang dikenali sebagai Pergerakan Gulen atau Hizmet. Pergerakan ini menjadi proksi kepada idealisme Gulen untuk memberi sumbangan dalam aspek pendidikan, dialog, keamanan, keadilan sosial dan keharmonian. Kemasyhurannya di Turkijuga membuat dia menjadi pencetus pergerakan sosial sekaligus merubah landskap politik Islam di Turki. Antara tumpuan utama Gulen, mereformasi masyarakat dengan memperuntukkan masa selama beberapa tahun membudayakan program dialog antara agama melalui sepuluh Institut Antara Agama di Eropah dan Amerika Syarikat. Kewujudan institusi ini membantu untuk meningkatkan hubungan yang lebih baik antara penganut agama. Selain itu, Gulen terlibat dalam mengetuai beberapa siri sosial yang berorientasikan kepada filantropi. Dalam mesej filantropi, Gulen selalu menekankan 'selagi mana tidak ada kekurangan dalam dunia ini, maka tiada siapa yang berhak untuk berada dalam kebuluran. ${ }^{48}$

Pemikiran Gulen dalam dialog antara agama bertitik tolak daripada pembentukan pendidikan awal beliau. Signifikan dengan pengaruh Said al-Nursi di kampungnya Gulen dibesarkan dalam Islamic culture lebih-lebih lagi bapanya sebagai seorang agamawan yang menitik beratkan soal agama kepada beliau. ${ }^{49}$

Keterlibatan dan komitmen Gulen dalam aktiviti dialog antara agama tidak asing lagi sejak sedekad yang lalu. Di Turki, Gulen sangat dihargai kerana telah membina persekitaran yang baik dalam menghubungkan komuniti agama khususnya antara majoriti Muslim dengan penganut agama minoriti seperti Greek Ortodoks, Armenia Ortodoks, Katolik, dan Yahudi. Manakala di luar Turki, idealisme Gulen tentang dialog antara agama berjaya menginspirasikan banyak pertubuhan dialog yang menekankan kepada objektif yang sama seperti persefahaman, penerimaan empati, keharmonian dalam kehidupan dan kerjasama. Atas sumbangannya yang signifikan dalam menyuburkan dialog dan sifat toleransi antara penganut agama, beliau mendapat pengiktirafan peribadi oleh Pope John Paul II, undangan daripada Ketua Rabbi Sephardic Israel dan pemimpin Kristian dari pelbagai mazhab untuk bersama-sama dalam perbincangan. ${ }^{50}$

\footnotetext{
${ }^{45}$ Ibid.

46 Ali Unal and Alphonse Williams, Advocate of Dialogue: Fetbullah Gülen (Fairfax: The Fountain, 2000), 9.

${ }^{47}$ M. Amin Abdullah: Muslim-Christian Relations: Reinventing the Common Ground to Sustain a Peaceful Coexistence in the Global Era. Draft paper yang disampaikan di 'the International Seminar on "The Vision of Fethullah Gülen and Muslim-Christian Relations”, St. Patrick's Campus, Australian Catholic University, Melbourne, Australia, 15-16 Juli 2009.

48 Ahmad Faizuddin ramli, pemikiran dan sumbangan fethula gulen dalam dialog antara agama, 34. Diakses dari bttps://www.researchgate.net/publication/318199905 Pemikiran dan Sumbangan Fethullah Gulen Dalam Dialog Antara Agama, 25 Desember 2018, 16:00.

${ }^{49}$ Ibid., 41.

50 Tudy D. Conway, Cross-Cultural Dialogue on the Virtues: The Contribution of Fethullah Gülen (Cham: Springer, 2014)
} 
Walaupun Gülen sempat mengakui adanya kesulitan yang mempersulit inisiasi dialog antar agama. Seperti, kecurigaan Umat Islam terhadap kelompok Kristen sebagai akibat konflik yang telah berlangsung berabad-abad. Kemudian, temuan Graham E. Fuller dan Ian O. Lesser yang telah dikutip Gülen, bahwa jumlah orang Islam yang dibunuh oleh bangsa Barat selama satu abad terakhir lalu jauh lebih besar dibanding jumlah orang Kristen yang dibunuh oleh Muslim selama rentang sejarah agama ini.29 Sementara itu di pihak Barat, seperti diungkapkan oleh Sidney Griffith30, memelihara cara pandang tertentu kepada Islam, misalnya, di universitasuniversitas Amerika, Islam tidak diajarkan sebagai agama di fakultas theologi, tetapi diajarkan satu sistem politik di departemen political science atau departemen hubungan internasional. ${ }^{51}$

Bagi Gulen, Agama dapat menjadi benteng pencegah kehancuran yang ditimbulkan oleh materialisme sains, menempatkan sains pada tempatnya, dan mengakhiri konflik berkepanjangan di antara manusia dan antar agama. ${ }^{52}$ Prinsip gerakan Gülen berusaha untuk tidak mengusung kembali masa lalu, mengagungkan romantisme masa awal Islam, tetapi menyegarkan modernitas dengan nilai-nilai tradisional. Tujuan Gülen adalah mendidik generasi yang memiliki kedalaman spiritual, terlibat dalam pengejaran intelektualitas, dan berkomitmen melayani seluruh manusia. Bagi Gülen, "melayani manusia berarti melayani Tuhan". ${ }^{53}$

Gulen juga dalam makalahnya Tolerance and Dialogue in the Perspective of the Qur'an and Sunna menjelaskan, bahwa al-Quran selalu menekankan sikap memaafkan dan toleransi sebagai prinsip utama, selaras dengan sifat golongan ibad al-Rahman (hamba kepada Yang Maha Pemurah). ${ }^{54}$ Karakter golongan c ibād al-Raḥmān dijelaskan dalam al-Quran; "Dan hamba-hamba (Allab) Ar-Rahman (yang diredai-Nya), ialah mereka yang berjalan di bumi dengan sopan santun dan apabila orang-orang yang berkelakuan kurang adab, hadapkan kata-kata kepada mereka, mereka menjawab dengan perkataan yang selamat dari perkara yang tidak diingini" (Surah alFurqan 25: 63).

Dalam ruang dialog, Gülen pun menegaskan, hidup bukan untuk mencari perbedaan tapi mencari persamaan ditengah perbedaan, seperti antara Islam dan Kristen: ${ }^{55}$ Islam dan Kristen muncul dari wilayah kebudayaan yang sama, yaitu Timur Tengah, samasama mengaku pewaris spiritualitas Ibrahim, kedua agama sama-sama memiliki etika monoteisme, Islam dan Kristen adalah agama sejarah, kedua agama merupakan agama wahyu, sama-sama mengajarkan bahwa wahyu datang melalui dua cara; kitab suci dan nabi. Kristen dan Islam merupakan agama yang memiliki kitab suci. Pemeluk keduanya akan menjadikan kitab suci mereka sebagai pedoman dan petunjuk, bagi kedua agama tersebut posisi nabi sangat penting, yang terakhir Islam memiliki kesamaan dengan Kristen dalam pandangannya terhadap agama Yahudi.

Dalam berdialog, Gulen meletakkan empat rukun utama; cinta, berbelas kasihan, toleransi dan memaafkan. Keempat rukun tersebut mempunyai nilai universal dalam tuntutan dalam agama. Umpamanya cinta yang merupakan elemen yang penting dalam setiap kehidupan. Ia menjadi pencetus dan pemangkin kepada pembinaan jiwa manusia. Melalui cinta, seseorang itu mampu bangkit dan memandu kepada tindakan seseorang. Peribadi yang mempunyai cinta yang tinggi pasti disebut dan dikenang walaupun selepas

\footnotetext{
${ }^{51}$ Unal and Williams, Advocate, 248.

52 Ali Unal and Alphonse Williams, 243.

53 Aslandogan "Present and Potential Impact of the Spiritual Tradition of Islam on Contemporary Muslims: From Ghazali to Gülen.”, 672.

54 Ahmad Faizuddin ramli, 38.

55 A. Rizqon Khamami, Dialog antar iman dalam Perspektif Fethullah Gülen, Religio, Vol.2, No.1 (Maret 2012), 10.
}

32 | Ananda Ulul Albab, - Interpretasi Dialog Antar Agama Dalam Berbagai Prespektif 
kematiannya. Cinta berakar dari hati dan sampai kepada hati seseorang. Sebagaimana para Nabi mengajarkan tentang cinta kepada umatnya, meskipun mereka ditolak oleh sebahagian dari kaumnya, wujud sebahagian umat lain yang menerima mereka. ${ }^{56}$

\section{Penutup}

Pada dasarnya setiap agama mengajarkan kebaikan, memberi cinta kasih, dan tidak menjelek-jelekkan agama lainnya atau orang yang tidak sepaham dengannya. Toleransi harus selalu dipupuk dalam diri setiap umat manusia guna merawat kerukunan dan agar tidak terjadi perpecahan di negeri ini. Dialog ialah slaah satu cara yang sangat ampuh dalam merawat kerukunan. Dengan dialog orang dari kalangan agama manapun dapat saling berkomunikasi tanpa takut tersinggung. Dialog baik menurut Hans Kug, Mukti Ali, fethula Gulen, dan Abu Nimer, semua bertujuan untuk menjadikan kehidupan lebih baik lagi. Walaupun kajian yang mereka lakukan berbeda-beda, tapi hakikat keinginan mereka sama. Karena orientasi dialog antar umat beragama adalah untuk menambah pengalaman yang ada dalam kearagaman serta mengusahakan dalam merealisasikan tujuan agama sebagai perdamaian dan perasaan kasih sayang. Dialog menjadikan umat antar pemeluk agama hidup rukun dan damai sesuai dengan keinginan dari tiap-tiap ajaran yang terdapat dalam agama-agama. Karena disamping itu dialog dapat meghindarkan adanya suatu prasangprasangka buruk terhadap pemeluk agama lain. Mengingat pada era globalisasi saat ini banyak isu-isu yang beredar di masyarakat dengan mengatas namakan agama untuk memecah umat beragama. Untuk itu dialog menjadi sangat penting untuk dijaga. Seperti halnya bersikap pluralisme di mana kita harus aktif dalam menghormati adanya perbedaan.

\section{Daftar Pustaka}

Abdullah, M. Amin: Muslim-Christian Relations: Reinventing the Common Ground to Sustain a Peaceful Coexistence in the Global Era. Draft paper yang disampaikan di "the International Seminar on "The Vision of FethullahGülen and Muslim-Christian Relations", St. Patrick's Campus, Australian Catholic University, Melbourne, Australia, 15-16 Juli 2009.

Abu-Nimer, Mohammed Amal Khoury and Emily Welty, Unity and Diversity (Washington, D.C.: United States Institute of Peace Press, 2007).

Ahmad, Saidiman, Husni Mubarak, dan Testriono. Pembaharuantanpa A pologia, Esaiesaitentang Ahmad Wahib. Jakarta: YayasanWakapParamadina. 2010.

Ali Mukti. Ilmu Perbandingan Agama, Dialog, Dakwah dan Misi. Yogyakarta: Pustaka Anwar. 1983.

Ali, Mukti. Agama, Moralitas dan Perkembangan Kontemporer. Yogyakarta: Tiara Wacana. 1997.

Ali, Mukti. Dialog Antar Agama. Yogyakarta: Yayasan Nida. 1970.

Arifin, Muhammad Zainal. Naskah Publikasi: Dialog Antar Agama dalam Pandangan Hans Kung. Diakses dari http://eprints.u-ms.ac.id/20437/22/NASKAH PUBLIKASI.pdf, 25 Desember 2018.

Armada, Riyanto. "Sebuah Studi Tentang Dialog Interreligius," dalam Diskursus, Vol. 9, No. 2 (Oktober 2010) Lih. Paul F. Knitter, Satu Bumi Banyak Agama: Dialog multiAgama dan Tanggung Jawab Global (Jakarta: BPK Gunung Mulia, 2012)

\footnotetext{
${ }^{56} \mathrm{Ahmad}$ Faizuddin ramli, pemikiran..., 39-40.
} 
Aslandogan "Present and Potential Impact of the Spiritual Tradition of Islam on Contemporary Muslims: From Ghazali to Gülen.", 672.

Azra, Azyumardi dan Saiful Umam. Menteri-menteri Agama RI, Biografi Sosial Politki. Jakarta: PPIM. 1989.

Banawiratma, J.B dkk,. Dialog Antarumat Beragama, Gagasan dan Praktik Di Indonesia. Jakarta: MizanPublika. 2010.

Bhaidawi, Zakiyuddin. Dialog Global danMasaDepan Agama. Surakarta: Muhammadiyah University Press. 2001.

Conway,Tudy D. Cross-Cultural Dialogue on the Virtues: The Contribution of FetbullabGülen (Cham: Springer, 2014)

Damma, M. "H.A. Mukti Ali: Ketaatan, Kesalehan dan Kecendekiaan" dalamDjam'annuri. 70 Tahun H.A. Mukti Ali: Agama dan Masyarakat.

Daya,Burhanuddin Agama Dialogis: Merenda Dialektika Idealita dan Realita Hubungan Antaragama, (Yogyakarta: Mataram Minang Lintas Budaya, 2004).

Daya,Burhanuddin dan Herman Leonard Beck,IlmuPerbandingan Agama Di Indonesia Dan Belanda, (Jakarta: Inis, 1992).

Faizuddinramli,Ahmad. Pemikirandansumbanganfethulagulendalam dialog antara agama. Diaksesdaribttps:// wmw.researchgate.net/publication/318199905 Pemikiran dan Sumbanga $n$ Fethullah Gulen Dalam Di-alog Antara Agama, 25 Desember 2018.

Harris, Sam. The End of Faith: Religion, Terror, and the Future of Reason. New York, NY: W. W. Norton, 2005.

Hayati, Muna. RETHINKING PEMIKIRAN A. MUKTI ALI (Pendekatan ScientificCum-Doctrinaire dan Konsep Agree in Disagreement), diakses dari https:// wwm.researchgate.net/publication/327600327 MENGINGAT KEMBALI PEMIKIRAN ABDUL MUKTI ALI PENDEKATAN SCIENTIFIC-CUMDOCTRIN-AIRE DAN K-ONSEP AGREE IN DISAGREEMENT, 25

Desember 2018.

Husain, Khaira. Etika Global; Sumbangan Hans Kung DALAM Dialog ANTAR Agama. Diaksesdaribttps:// media.neliti.com/ media/publications/40304-ID-etika-global-sumbangan-hanskung-dalam-dialog-antar-agama.pdf, 25 Desember 2018.

Izah, Lathifatul. Melihat Potret Harmonisasi Hubungan Antar umat Beragama Di Indonesia". Religi. Vol IX, No. 1. Januari 2013.

Khamami, A. Rizqon. Dialog antarimandalamPerspektifFethullahGülen, Religio, Vol.2, No.1 (Maret 2012).

Khamami, Akhmad Rizqon. "Dialog Antar Iman Sebagai Resolusi Konflik, Tawaran Mohammed Abu-Nimer". Al-Tabrir. Vol 14, No. 2. Mei 2014.

Khambali, Khadijah Mohd dan NurhanisahSenin, Citra Dialog Antar Agama dalamPerspektif Islam dan Kristian: AnalisisAwal, diaksesdarihttp://journalarticle.ukm.my/5957/1/j.pdf,pada 25 Desember 2018.

Kung, Hans. "PerdamaianDunia, Agama-Agama Dunia, EtikaDunia". Terj Ali Noer Zaman Agama Untuk Manusia.

Kung, Hans dan Karl Josef Kuschel. Etika Global (Yogyakarta: PustakaPelajar, 1999).

Kung,Hans. "Sebuah Model Dialog Kristen-Islam" dalamJurnalParamadina (Jakarta, ParamadinaJuli-Desember, 1995).

Majid, Nur cholish. Islam DoktrindanPeradaban. Jakarta: Paramadina. 1992.

Nimer, Mohammed Abu, Amal Khoury and Emily Welty. Unity and Diversity. Washington, D.C. United States Institute of Peace Press, 2007

34 | Ananda Ulul Albab, - Interpretasi Dialog Antar Agama Dalam Berbagai Prespektif 